\title{
ANÁLISE DE PALINOFÁCIES EM SEDIMENTOS HOLOCÊNICOS DA LAGOA DOS QUADROS, RIO GRANDE DO SUL, BRASIL
}

\author{
KARIN ELISE BOHNS MEYER \\ PPG-Geociências, UFRGS, Av. Bento Gonçalves, 9500, 91540-000, Porto Alegre, RS, Brasil. bohnsmeyer@yahoo.com.br \\ JOÃO GRACIANO MENDONÇA FILHO \\ Instituto de Geociências, UFRJ, Av. Brigadeiro Trompowski s/n, 21940-900, Ilha do Fundão, Rio de Janeiro, RJ, Brasil. \\ graciano@geologia,ufrj.br
}

ABDUL RAHMAN ASHRAF
Institut für Geowissenschaften, Universität Tübingen, Sigwartstraße 10, D - 72076, Tübingen, Deutschland.

rahman.ashraf@uni-tuebingen.de

PAULO ALVES DE SOUZA

Laboratório de Palinologia, IG, UFRGS, C.P. 15.001, 91509-900, Porto Alegre, RS, Brasil.paulo.alves.souza@ufrgs.br

\section{KARIN REICHHART}

Johann Wolfgang Goethe Universität, Institut für Geolögie und Paleontologie, Senckenberganlage, 32-34, D- 60054,

Frankfurt, Deutschland.karin-reichhart@gmx.de

RESUMO - Mudanças ambientais durante o Holoceno foram interpretadas na Planície Costeira Norte do Rio Grande do Sul com base no testemunho de sondagem QU-RS-B09 da lagoa dos Quadros. A análise de palinofácies foi realizada em quarenta e uma amostras sedimentares selecionadas ao longo dos $405 \mathrm{~cm}$ do testemunho de sondagem datado em $6.700 \pm 40$ anos $\mathrm{AP}$, à profundidade de $375 \mathrm{~cm}$ e em $4.870 \pm 40$ anos $\mathrm{AP}$, à profundidade de $75 \mathrm{~cm}$. A análise de agrupamento do modo- $Q$ permitiu a identificação de seis agrupamentos que, plotados estratigraficamente, possibilitaram a caracterização de três intervalos, com palinofácies características, que correspondem a diferentes ambientes na evolução holocênica do corpo lagunar. O intervalo 1A, caracterizado por uma palinofácies com predomínio de matéria orgânica amorfa (MOA), fitoclastos opacos e não opacos, está associado ao Sistema Lagunar em Fase Transgressiva. O intervalo 1B em cuja palinofácies dominam fitoclastos opacos, MOA e fitoclastos não opacos, está associado ao Sistema Lagunar e o Máximo Transgressivo Lagunar. O intervalo 2, com predomínio de MOA e Botryococcus braunii, caracteriza o Sistema Lagunar em Fase Regressiva, com aumento nos percentuais de grãos de pólen e esporos em direção ao topo, de condições semelhantes às atuais, de lago costeiro.

Palavras chave: palinofácies, Holoceno, mudanças do nível relativo do mar, lagoa dos Quadros, Planície Costeira do Rio Grande do Sul.

ABSTRACT - PALYNOFACIES ANALYSIS IN HOLOCENIC SEDIMENTS OF QUADROS LAGOON, RIO GRANDE DO SUL PLAIN, BRAZIL. The interpretation of environmental changes during the Holocene on the North Rio Grande do Sul Coastal Plain, is based on the core QU-RS-B09 of Quadros lagoon record. The palynofacies analysis was carried out in 41 sedimentary samples along the $405 \mathrm{~cm}$ of the core, dated of $6.700 \pm$ 40 years BP at $375 \mathrm{~cm}$ deep and in $4.870 \pm 40$ years BP $75 \mathrm{~cm}$ deep. $Q$-mode cluster analysis provided the identification of six groupings which stratigraphically plotted allowed the characterization of three intervals with palynofacies features corresponding to different environments in the holocenic evolution of the lagoon. Interval $1 \mathrm{~A}$, characterized by a palynofacies predominantly comprised of Amorphous Organic Matter (AOM), opaque and non-opaque phytoclasts, is associated to a Lagoon System in a Transgressive Phase. Interval 1B, whose palynofacies corresponds to opaque phytoclasts, MOA and non-opaque phytoclasts characterizes the Lagoon System and the Lagoon Maximum Transgressive (PGMT). Interval 2, predominantly comprised of AOM and Botryococcus braunii, characterizes the Lagoon System in a Regressive Phase, having an increase of pollen grains and spore percents towards the top, which characterizes conditions similar to the present coastal lake.

Key words: palynofacies, Holocene, sea level changes, Quadros lagoon, Rio Grande do Sul Coastal Plain. 


\section{INTRODUÇÃO}

As variações paleoclimáticas e as mudanças do nível relativo do mar são fatores que influenciam a evolução das áreas costeiras, com reflexos significativos na Planície Costeira do Rio Grande do Sul. Eventos de larga escala (transgressões/regressões) que delimitam ambientes marinhos e não marinhos podem ser identificados pela utilização de marcadores palinológicos, como a ocorrência de fitoplâncton marinho (e.g., cistos de dinoflagelados) e de palinofácies, pela deposição de diferentes conjuntos de palinomorfos e matéria orgânica particulada de origem terrígena e marinha (Traverse, 1994).

A caracterização qualitativa e quantitativa da matéria orgânica particulada contida nos sedimentos e nas rochas sedimentares constitui a análise de palinofácies. Esta técnica visa à identificação dos componentes particulados individuais, a determinação de suas proporções relativas e absolutas, incluindo suas dimensões e seu estado de preservação. Dessa forma, a análise das distintas palinofácies identificadas dentro de uma seqüência deposicional, que apresenta modificações nas fácies relacionadas com as variações do nível do mar e influência terrígena, assume grande importância nas reconstituições ambientais.

No contexto da estratigrafia de seqüências, as palinofácies podem representar distintas características dos tratos de sistemas, como por exemplo, a progressão das fácies de ambiente proximal a distal (Tyson, 1996). A distribuição da matéria orgânica particulada é bem conhecida para os ambientes marinhos de seqüências pré-quaternárias, representadas principalmente por fácies plataformais proximais e distais e de talude (e.g., Tyson, 1995, 1996; Gregory \& Hart, 1990; Pasley et al., 1991; Carvalho, 2001) do que para seqüências quaternárias (e.g., Menezes, 2002).

Pouco se sabe sobre a caracterização dos parâmetros de palinofácies em depósitos lagunares/lacustres de áreas costeiras brasileiras que evoluíram sob influência das variações do nível relativo do mar. O principal objetivo deste trabalho é a caracterização da matéria orgânica particulada contida em amostras do testemunho de sondagem da lagoa dos Quadros (QU-RS-B09) e o uso das palinofácies identificadas na interpretação dos ambientes deposicionais durante a evolução holocênica na lagoa e sua correlação com os eventos geológicos conhecidos para a Planície Costeira Norte do Rio Grande do Sul (PCNRS).

\section{CONTEXTO GEOLÓGICO}

A Planície Costeira do Rio Grande do Sul (PCRS) é uma área de terras baixas com cerca de $33.000 \mathrm{~km}^{2}$, correspondente à região de exposição dos depósitos superiores e proximais da seqüência sedimentar acumulada na bacia de Pelotas (Tomazelli \& Villwock, 2000).

A bacia de Pelotas ocupa uma área de $70.000 \mathrm{~km}^{2}$, que se estende desde o sul da plataforma de Florianópolis até o lineamento de Chuí (Ghignone, 1960). A origem da bacia está rela- cionada a eventos tectônicos ocorridos durante o Eocretáceo e que provocaram a abertura do Oceano Atlântico Sul. Seus depósitos cobrem o embasamento, constituído pelo complexo cristalino pré-cambriano, e seqüências sedimentares e vulcânicas paleozóicas e mesozóicas da bacia do Paraná.

Durante o Quaternário, na PCRS ocorreu o desenvolvimento de um amplo sistema de leques aluviais, na parte mais interna, e o acréscimo de quatro sistemas deposicionais do tipo laguna-barreira, denominados, respectivamente, Sistemas Laguna-Barreira I, II, III e IV (Villwock, 1984; Villwock \& Tomazelli, 1995; Tomazelli \& Villwock, 2000). De acordo com Tomazelli \& Villwock (2000), os sistemas deposicionais pleistocênicos do tipo Laguna-Barreira I, II e III estão relacionados aos estágios isotópicos do oxigênio 11, 9 e 5 respectivamente. O mais recente, Sistema Laguna-Barreira IV, ao qual está associada a formação da lagoa dos Quadros, está relacionado ao estágio isotópico do oxigênio 1, no contexto da Última Transgressão Marinha, cujo máximo foi atingido em torno dos 5.100 anos AP. A Barreira IV ocupa uma extensão de $620 \mathrm{~km}$ ao longo da costa do Rio Grande do Sul. Descontinuidades no sistema da barreira ocorrem em dois pontos: ao sul, no canal de comunicação da lagoa dos Patos com o Oceano, e ao norte, na laguna de Tramandaí. Fotos aéreas, imagens de satélite e mapeamento geológico mostram mudanças marcantes no estilo de desenvolvimento da costa durante o Holoceno médio e tardio que possibilitaram a identificação de cinco setores, denominados respectivamente de norte a sul, ao longo dos 620 km da Barreira IV, setores 1, 2, 3 , 4 e 5, (Dillenburg et al., 2000). Segundo estes autores, o setor 1 , que corresponde à área da costa entre Torres e Tramandaí, no extremo norte da PCRS, é levemente côncavo com uma barreira holocênica formada por uma planície de cordões de dunas de 2 a 5 $\mathrm{km}$ de largura.

O cordão a oeste é o mais alto e foi interpretado como uma barreira transgressiva relacionada ao Último Máximo Transgressivo. Uma faixa de aproximadamente $1 \mathrm{~km}$ de dunas transgressivas ocorre continuamente próxima à linha de praia atual, entre Torres e Xangrilá, onde as dunas são mais longas e eventualmente cobrem a superfície da barreira. Dunas transgressivas representam uma perda de areia da costa em direção ao continente, indicando a retração da costa. Estes depósitos foram interpretados como registros de uma barreira progradante e barreira composta transgressiva progradante com dunas transgressivas, correspondentes aos tipos de barreira B e C, identificados por Dillenburg et al. (2000). De acordo com Dillenburg et al. (no prelo), a barreira holocênica na localidade de Curumim (Barreira IV) iniciou a progradação em torno de 7.000 anos AP, devido ao balanço positivo na acomodação dos sedimentos, quando o nível relativo do mar ainda estava subindo, no período próximo ao final da Última Transgressão Marinha. A instalação da Barreira IV está diretamente relacionada ao Último Máximo Transgressivo atingido há cerca de 5.100 anos AP (Dillenburg et al., no prelo). 
As variações do nível relativo do mar durante o Quaternário na costa do Rio Grande do Sul têm registros desde o Pleistoceno. Segundo Corrêa (1995), o nível relativo do mar esteve entre 120 a $130 \mathrm{~m}$ abaixo do nível atual há cerca de 17.500 anos AP. Desde então, o nível subiu cerca de 0,6 cm/ano, no período entre 14.000 e 12.000 anos AP, 1,9 $\mathrm{cm} /$ ano entre 8.000 e 6.500 anos AP e níveis mais altos após o começo da Última Transgressão Marinha em ca. 5.100 anos AP. De acordo com Dillenburg et al. (2000, no prelo), não há dados disponíveis a respeito da curva da variação do nível do mar durante o Holoceno médio e tardio ao longo da costa do Rio Grande do Sul. No entanto, os autores reconhecem que os padrões gerais das curvas de variação do nível relativo do mar, delineadas em outros setores da costa brasileira, podem ser aplicados para o Rio Grande do Sul.

Em linhas gerais, as curvas de flutuação do nível relativo do mar, delineadas em vários trechos do litoral brasileiro, para o Holoceno, mostram uma mesma configuração, indicando uma fase transgressiva até aproximadamente 5.100 anos AP. A partir deste datum, a maioria dos dados indica uma tendência regressiva (e.g., Suguio et al., 1985; Angulo \& Lessa, 1997; Martin et al., 1998).

A curva de Martin et al. (1979) mostra que o máximo nível relativo do mar foi de $+5 \mathrm{~m}$ na Costa da Bahia. Os resultados de Ângulo \& Lessa (1997) sugerem que o máximo nível relativo do mar foi de $+3,5 \mathrm{~m}$ na Costa do Estado de São Paulo e no Paraná. Finalmente, Angulo et al. (1999) sugerem que a inundação máxima foi de $+2 \mathrm{~m}$ durante o Ultimo Máximo Transgressivo em Santa Catarina, a $100 \mathrm{~km}$ da costa do Rio Grande do Sul.

A identificação da altitude máxima das fácies praiais durante a progradação da Barreira IV na localidade de Curumim, possibilitou a estimativa do máximo nível relativo do mar, de aproximadamente $+4 \mathrm{~m}$, no intervalo de tempo entre 6.700 e 5.200 anos AP na PCNRS (Dillenburg et al., no prelo).

\section{MATERIAL E MÉTODOS}

Do testemunho de sondagem QU-RS-B09 (2.588. 613 $\mathrm{E} ; 6.717 .591 \mathrm{~N})$, coletado com aparelho do tipo vibrocore, na lagoa dos Quadros (Figura 1), foram selecionadas, 41 amostras, ao longo de $405 \mathrm{~cm}$ de profundidade, para o estudo de palinofácies e palinológico (Figura 2). O tratamento químico das amostras foi realizado no Laboratório de Palinologia do Instituto de Geociências da Universidade de Tübingen, Alemanha, de acordo com os procedimentos palinológicos não oxidantes descritos por Tyson (1995), Mendonça Filho (1999) e Mendonça Filho et al. (2002), que consistem, basicamente, no tratamento com ácido clorídrico e fluorídrico para eliminação da fração mineral e na separação e concentração da matéria orgânica do resíduo mineral com cloreto de zinco.

A fração maior que $6 \mu \mathrm{m}$ foi concentrada para a montagem de lâminas em meio de gelatina glicerinada. As lâminas estão depositadas na Palinoteca do Museu de Paleontologia do Departamento de Paleontologia e Estratigrafia do Instituto de Geociências da UFRGS, sob a numeração MP-P 5011 a 5052 .

A classificação da matéria orgânica particulada foi feita em microscopia de luz branca transmitida sob aumentos de 250 e 400x. A intensidade relativa da fluorescência dos componentes da matéria orgânica foi avaliada com o uso de luz azul incidente no microscópio Olympus BX-51 do Laboratório de Palinologia do Departamento de Paleontologia e Estratigrafia do IG da UFRGS. Na caracterização da intensidade de fluorescência da matéria orgânica foram atribuídos valores, que variam de 1 a 6 , de acordo com a escala numérica de Tyson (1995).

Duas contagens foram realizadas, a primeira de palinofácies, considerando toda a matéria orgânica particulada até 300 partículas, e a segunda visando a determinação da freqüência relativa dos táxons reconhecidos no conjunto de palinomorfos.

\section{Análise de Palinofácies}

O estudo de palinofácies consistiu da análise qualitativa e quantitativa dos diferentes componentes da matéria orgânica particulada baseada no sistema de classificação proposto por Tyson (1995), com adaptações introduzidas (Figura 3). De acordo com esta classificação, a matéria orgânica particulada é referente a três grupos: palinomorfos, fitoclastos e matéria orgânica amorfa (MOA).

Os palinomorfos foram divididos em esporomorfos, de origem terrestre (esporos e grãos de pólen), microplâncton de parede orgânica (algas e cianobactérias), zoomorfos (palinoforaminíferos e ovos de platelmintos) e esporos de fungos.

Os fitoclastos foram classificados em opacos (de coloração preta até nas porções marginais da partícula) e não opacos (de coloração amarela escura a marrom). Os fitoclastos não opacos e opacos foram subdivididos em categorias de acordo com sua morfologia, presença ou ausência de elementos estruturais, e estado de preservação. O primeiro grupo dos fitoclastos está representado por fitoclastos opacos equidimensioniais, alongados, corroídos e bioestruturados. Os fitoclastos não opacos foram classificados em fitoclastos não opacos bioestruturados estriados, cutículas e fitoclastos não opacos não bioestruturados. Os fitoclastos não opacos bioestruturados estriados têm sua origem em tecidos de vegetais superiores e, quando observados em luz branca transmitida, apresentam coloração em diversas tonalidades de marrom, com contornos angulares a levemente corroídos.

As cutículas, que são fragmentos da epiderme de folhas de vegetais superiores, apresentam coloração amarela e marrom, com excelente preservação das estruturas celulares características das epidermes. Em geral, as cutículas se apresentam não degradadas, com contornos nítidos. Os fitoclas- 


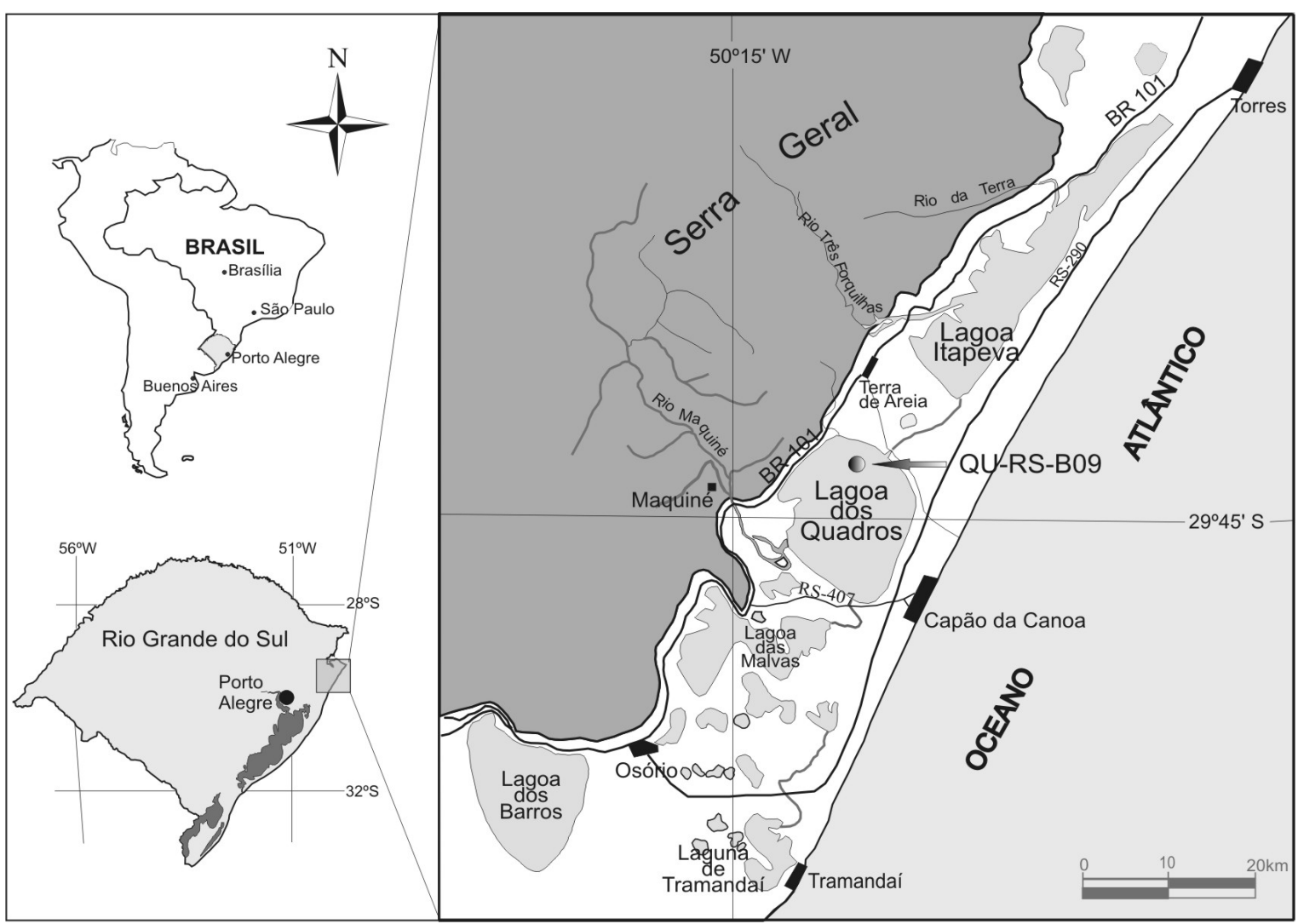

Figura 1. Mapa de localização da lagoa dos Quadros e do testemunho de sondagem QU-RS-B09, Planície Costeira do Rio Grande do Sul, Brasil. Figure 1. Location map of Quadros lagoon and QU-RS-B09 core, Rio Grande do Sul Coastal Plain, Brazil.

tos não opacos e não bioestruturados são partículas que não possuem estrutura botânica interna, de coloração marrom-clara, equidimensionais quanto à forma, com contornos nítidos ou levemente irregulares e lascados.

A MOA é caracterizada pela ausência de estruturação, contorno irregular e matriz granular heterogênea. Ocorre sob a forma de grumos ou dispersa, com diferentes tonalidades de marrom, quando analisada sob microscopia óptica de luz branca transmitida.

\section{Análises de agrupamento e coeficiente r-Pearson}

$\mathrm{O}$ tratamento estatístico consistiu em análises de agrupamento modo- $Q$ e modo- $R$, realizadas pelo Software Statistica 6.0 (Statsoft Inc.), a partir dos percentuais relativos dos componentes da matéria orgânica particulada. Ambos os métodos contemplam a reunião, em agrupamentos, de diferentes tipos de componentes da matéria orgânica particulada que, nas amostras analisadas, apresentassem padrão de distribuição equivalente. $\mathrm{O}$ coeficiente de correlação linear de Pearson ( $r$-Pearson) foi empregado para quantificar a dependência linear entre os elementos e, assim, determinar a matriz de correlação, pela qual os valores mais próximos a +1 correspondem ao maior grau de correlação, enquanto aqueles próximos de -1 apontam um menor grau de correlação entre as amostras (Valentin, 2000).

\section{PRINCIPAIS PARÂMETROS EM PALINOFÁCIES}

A aplicação da técnica de palinofácies na caracterização de paleoambientes consiste na utilização de parâmetros obtidos a partir da análise qualitativa e quantitativa da matéria orgânica particulada. Estes parâmetros representam tendências de dispersão de seus componentes, controladas por fatores ambientais, tais como: processos deposicionais, hidrodinâmica, influxo fluvial, variações do nível relativo do mar, entre outros. Em linhas gerais, fornecem informações a respeito do aporte fluvial (fitoclastos opacos e não opacos, grãos de pólen e esporos e razão esporo/pólen); condições desóxicas-anóxicas a óxicas (Matéria Orgânica Amorfa-MOA); influência marinha (cistos de dinoflagelados e palinoforaminíferos) e tendências eutróficas ou oligotróficas do corpo lagunar [Botryococcus, Pediastrum e razão Botryococcus/Pediastrum (razão BOT/PED)].

As tendências na distribuição dos componentes da matéria orgânica particulada, que caracterizam as palinofácies, refletem a atuação de condicionantes que indicam, sobretudo, a natureza proximal ou distal das fácies estudadas. Dessa forma, os elementos mais importantes são: a produtividade primária terrestre na área fonte; a natureza, a eficiência (taxa de descarga) e a duração relativa do processo de transporte 


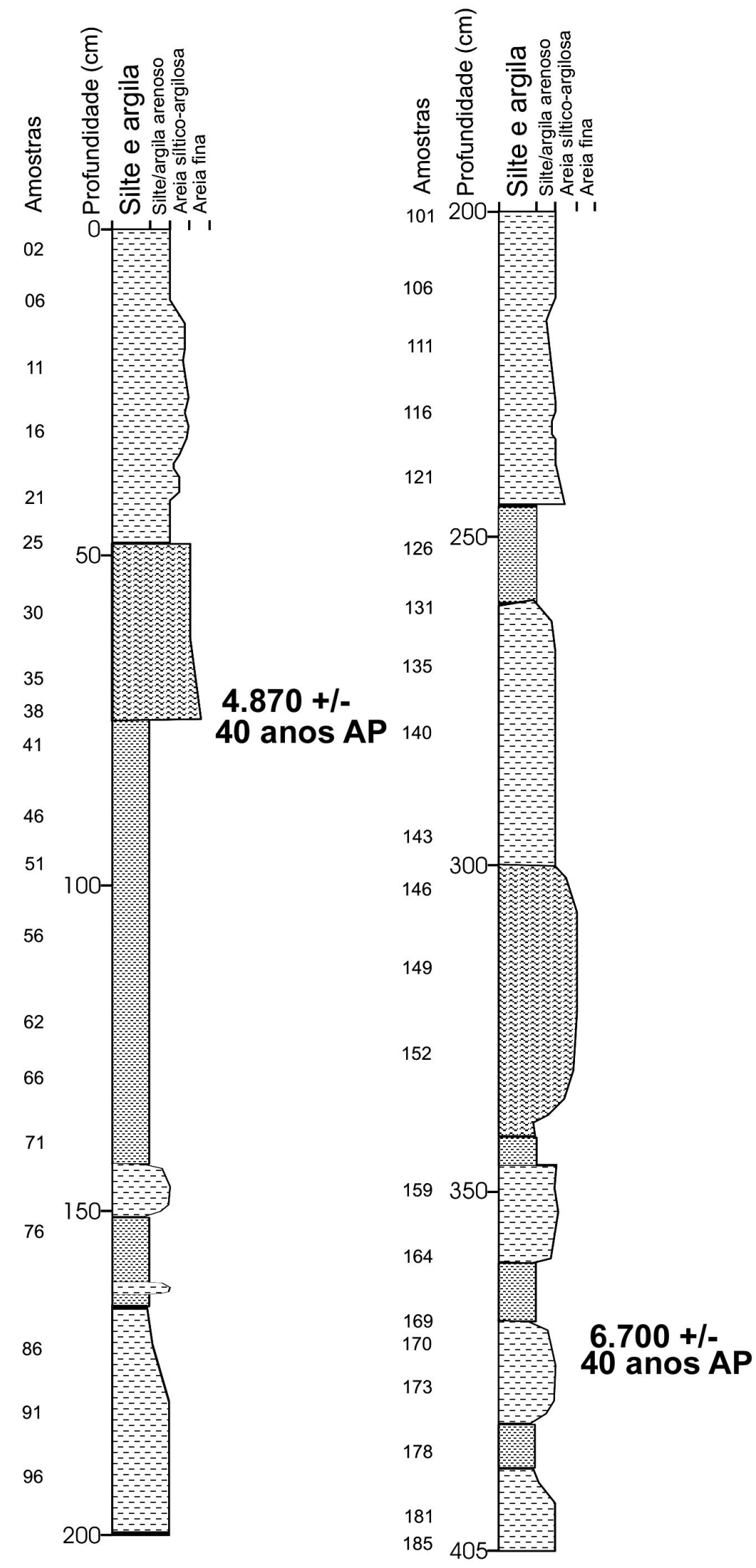

Figura 2. Perfil estratigráfico do testemunho de sondagem QU-RS-B09.

Figure 2. Stratigraphic profile of QU-RS-B09 core. 


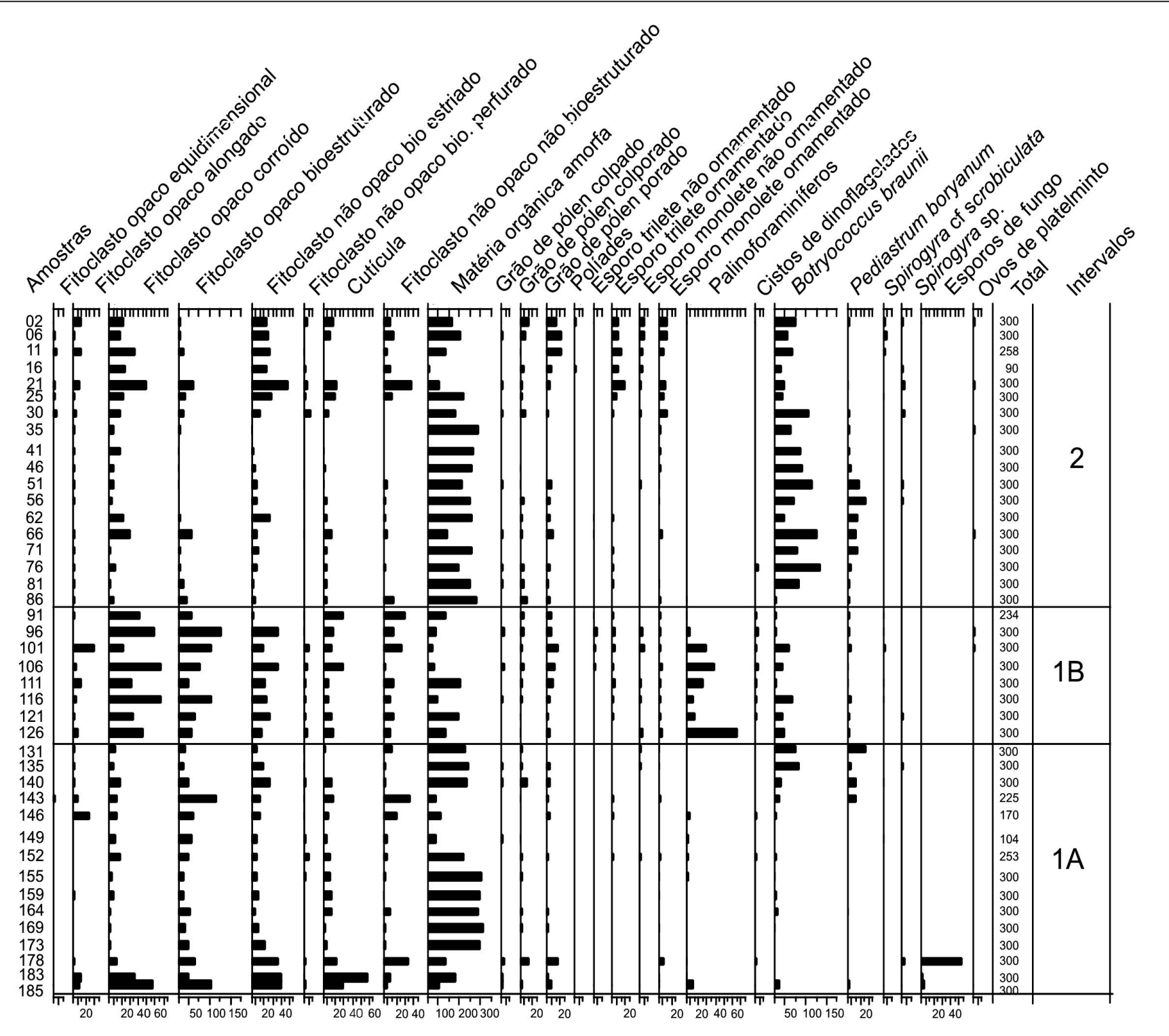

Figura 3. Freqüência absoluta dos componentes da matéria orgânica particulada nas amostras do testemunho QU-RS-B09.

Figure 3. Frequency of particulate organic matter in QU-RS-B09 core samples.

entre a área fonte e o sítio deposicional; e a distância relativa entre a área fonte dos sedimentos siliciclásticos (e.g., flúvio-deltaicos), e/ou entre a fonte da matéria orgânica terrestre (fitoclastos) e o sítio deposicional.

Assim, o predomínio de fitoclastos não opacos no conjunto da matéria orgânica particulada indica origem proximal das fácies e condições óxicas do ambiente, com proximidade da fonte fluvial. Percentuais elevados de fitoclastos não opacos são usualmente encontrados próximos a fontes fluviais, onde, a partir da ação das correntes que transportam estas partículas, ocorre dispersão dos fitoclastos opacos, palinomorfos ou da matéria orgânica amorfa em suspensão. Existe um decréscimo geral nos percentuais de fitoclastos não opacos no sentido distal, conforme aumenta a distância da área fonte.
Os fitoclastos opacos apresentam maior resistência à degradação em relação aos fitoclastos não opacos e permanecerão no ambiente deposicional após a destruição seletiva da maioria dos outros componentes da matéria orgânica particulada. Percentuais elevados de fitoclastos opacos estão associados a sedimentos de granulometria grossa e ambientes oxidantes de alta energia, como deltas e fácies de plataforma costeira (Tyson, 1993).

Percentuais significativos de esporos no conjunto dos palinomorfos indicam o desenvolvimento de vegetação pteridofítica e/ou a maior contribuição desta vegetação, condições úmidas na área fonte e transporte em meio aquoso. Os grãos de pólen podem ser dispersos por insetos (entomofilia), vento (anemofilia) e água (hidrofilia) e são encontrados 
nos mais variados ambientes deposicionais (Bauermann et al., 2002).

No ambiente lacustre os grãos de pólen recuperados dos sedimentos de fundo são dispersos por via aérea ou aquática, sendo a primeira forma mais significativa em lagos com menos de $100 \mathrm{~m}$ de diâmetro areal, nos quais há predomínio de grãos de pólen da vegetação local ou extra-local. Nos sistemas estuarinos, o conjunto de esporomorfos é transportado, principalmente, pelos rios tributários (e.g., Bauermann et al., 2002).

Percentuais elevados de MOA são característicos de áreas de alta preservação com condições redutoras e de baixa energia, especialmente em áreas afastadas da influência flúvio-deltaica. De acordo com Tyson (1995), em condições onde há deficiência de $\mathrm{O}_{2}$ (desóxica/anóxica), ocorre preservação dos componentes lábeis, ricos em hidrogênio, que fluorescem quando expostos à excitação de luz azul ou ultravioleta. Outra característica importante indicadora do tipo de matéria orgânica original e dos processos pós-deposicionais sofridos por estes componentes orgânicos, é a intensidade e coloração da fluorescência da matriz de partículas amorfas heterogêneas. Como a matriz da matéria orgânica amorfa é mais facilmente oxidada, a resposta total da fluorescência, incluindo as inclusões de outros tipos de partículas orgânicas, vai refletir a natureza do plâncton e dos processos oxidativos do ambiente deposicional (Tyson, 1995).

A influência marinha é identificada por marcadores palinológicos, tais como cistos de dinoflagelados e palinoforaminíferos. Os primeiros são componentes do microplâncton, sendo $90 \%$ das espécies de dinoflagelados marinhas e 10\% de água doce, com distribuição variável nos diversos ambientes e predominância na plataforma continental. Os palinoforaminíferos correspondem à película interna de composição quitinosa/tectinosa que reveste a carapaça destes protozoários e seu registro indica condições marinhas. De acordo com Stancliffe (1989), altas concentrações de palinoforaminíferos em sedimentos atuais são comuns em áreas de ressurgência, com altos percentuais de nutrientes, em águas rasas, com menos de $7 \mathrm{~m}$ de profundidade, e em águas com maior salinidade.

De acordo com Tyson (1995), a curva dos percentuais da razão BOT/PED pode ser utilizada para inferir condições eutróficas e/ou oligotróficas nos corpos lacustres e lagunares. Para este autor, os aumentos nos valores percentuais da curva seriam indicativos de condições oligotróficas e os decréscimos indicativos de condições eutróficas. A utilização das variações da curva da razão $\mathrm{BOT} / \mathrm{PED}$ está baseada no fato de que Pediastrum e Botryococcus ocorrem freqüentemente nos mesmos ambientes. No entanto, ambas algas não são simultaneamente abundantes, sugerindo preferências ecológicas distintas. De acordo com Tyson (1995), Pediastrum se desenvolve em ambientes com alta taxa de nutrientes, estenohalinos, associada a lagos eutróficos. Já Botryococcus seria uma forma eurihalina, que apresenta diminuição na atividade fotossintética quando a salinidade aumenta, de efeito inibitório, embora não letal (Bauld et al, in Tyson, 1995).

\section{RESULTADOS}

\section{Descrição do testemunho QU-RS-B09}

A testemunhagem QU-RS-B09 recuperou integralmente os $405 \mathrm{~cm}$ perfurados (Figura 2). No intervalo, dominam sedimentos siltosos e argilosos, de espessuras variáveis, nos quais são comuns lentes centimétricas de areia.

\section{Datações radiocarbônicas}

Datações radiocarbônicas foram realizadas pela técnica de espectrometria de acelerador de massa (AMS) no Beta Analytic Inc. Lab., Miami, Flórida, EUA. Ao longo do testemunho duas amostras foram datadas, à profundidade de 375 $\mathrm{cm}$, que acusou $6.700 \pm 40$ anos AP e à $75 \mathrm{~cm}$ de profundidade, com idade de $4.870 \pm 40$ anos AP.

\section{Distribuição dos grupos da matéria orgânica particulada}

Os resultados da distribuição quantitativa e da caracterização dos grupos da matéria orgânica particulada nas amostras estudadas estão sintetizados na Figura 3.

No grupo dos fitoclastos opacos foi constatado o predomínio de elementos corroídos, de forma irregular e degradada e de elementos bioestruturados, que mostram a estrutura típica de tecidos vegetais, como lúmen celular, perfurações, etc., em relação aos alongados e equidimensionais. Considerando a distribuição de fitoclastos opacos por intervalo estratigráfico, foi verificada maior freqüência destas partículas durante a fase transgressiva, nos intervalos 1A e 1B (Figura 3).

Dentre os fitoclastos não opacos, a freqüência de fitoclastos não opacos bioestruturados estriados foi maior em relação às cutículas e fitoclastos não opacos não bioestruturados. Os fitoclastos não opacos são o terceiro grupo da matéria orgânica particulada em ocorrência durante a fase transgressiva. Os fitoclastos não opacos têm fluorescência mais fraca, de coloração amarelo escura a laranja, enquanto que as cutículas mostram fluorescência amarelo clara.

$O$ registro de MOA foi mais significativo durante a fase transgressiva, diminuindo durante o máximo transgressivo lagunar e apresentando altos percentuais durante a fase regressiva. A MOA têm fluorescência variável ao longo da seqüência sedimentar, correspondente aos níveis 3, 4 e 5, de acordo com a escala de Tyson (1995).

Os palinomorfos de origem terrestre, esporos e grãos de pólen apresentaram a menor distribuição durante a fase transgressiva e maior distribuição durante a fase regressiva. Os esporos e grãos de pólen apresentam fluorescência amarelo intensa, menos intensa que a das algas (Botryococcus e Pediastrum), de fluorescência amarelo esverdeada.

A identificação taxonômica das algas contribuiu para a caracterização detalhada das diferentes condições ambien- 
tais na seqüência sedimentar (Figura 4), tendo sido identificadas (Anexo 1): Botryococcus braunii (Figura 4A), Pediastrum boryanum (Figura 4B e C), Spiniferites mirabilis (Figura 4D) e Operculodinium centrocarpum (Figura 4 E).

\section{Análises de agrupamento}

As análises de agrupamento utilizadas foram as do modo- $Q$ e modo- $R$, realizadas a partir dos percentuais relativos dos componentes da matéria orgânica particulada. Os resultados das análises de agrupamento são representados em dendogramas, que são diagramas ramificados que contém entidades reunidas por determinado critério (Wiley, 1981). O dendograma obtido da análise de agrupamento modo- $R$ (Figura 5) permitiu a separação de cinco agrupamentos formados pelos diferentes componentes da matéria orgânica particulada. Estes agrupamentos apontam correlações entre os componentes que dizem respeito à equivalência hidrodinâmica. Desta forma, Pediastrum, Botryococcus e MOA constituem o agrupamento 1. O agrupamento 2 é formado por esporos de fungo e Spirogyra cf scrobiculata. Já o agrupamento 3 evidenciou a equivalência hidrodinâmica entre Spirogyra sp., esporos, grãos de pólen e fitoclastos não opacos. O agrupamento 4 mostra a equivalência hidrodinâmica entre ovos de platelmintos, palinoforaminíferos e cistos de dinoflagelados. O quinto agrupamento mostra a equivalência hidrodinâmica entre cutículas, resinas e fitoclastos opacos. Estes dados são preliminares e requerem estudos mais detalhados, como por exemplo, os que envolvem a caracterização do tamanho dos componentes orgânicos particula- dos, de forma a evidenciar a relação entre os componentes apontadas na análise de agrupamento do modo- $R$.

O dendograma produzido a partir da análise de agrupamento modo- $Q$ (Figura 6) mostra seis agrupamentos, baseados nos dados de freqüência relativa dos componentes da matéria orgânica. Os seis agrupamentos estão divididos em dois grandes agrupamentos (Figura 6) com menor grau de similaridade. Esta divisão reflete claramente a influência marinha nos agrupamentos 5 e 6 .

A partir da análise da média percentual dos diferentes componentes da matéria orgânica particulada (Anexo 2), foram identificados os parâmetros de palinofácies significativos na caracterização das condições ambientais indicadas pelas amostras de cada um dos seis agrupamentos. Os parâmetros analisados foram: influxo fluvial (média percentual de fitoclastos opacos, fitoclastos não opacos e esporomorfos), condições redutoras e tendência desóxica-anóxica (média percentual de MOA) e influência marinha (média percentual de cistos de dinoflagelados e palinoforaminíferos). De acordo com estes parâmetros, os seis agrupamentos obtidos da análise de agrupamento do modo- $Q$ podem ser interpretados, de acordo com seu significado ambiental como segue:

Agrupamento 1. Caracterizado pelo predomínio de MOA $(58,4 \%)$. A média dos elementos indicativos de influxo fluvial é de $31,2 \%$. A influência marinha é observada em apenas uma das seis amostras do grupo (amostra 152).

Agrupamento 2. Apresenta média percentual de MOA é de $67,1 \%$. Botryococcus braunii com $19 \%$ é o segundo componen-

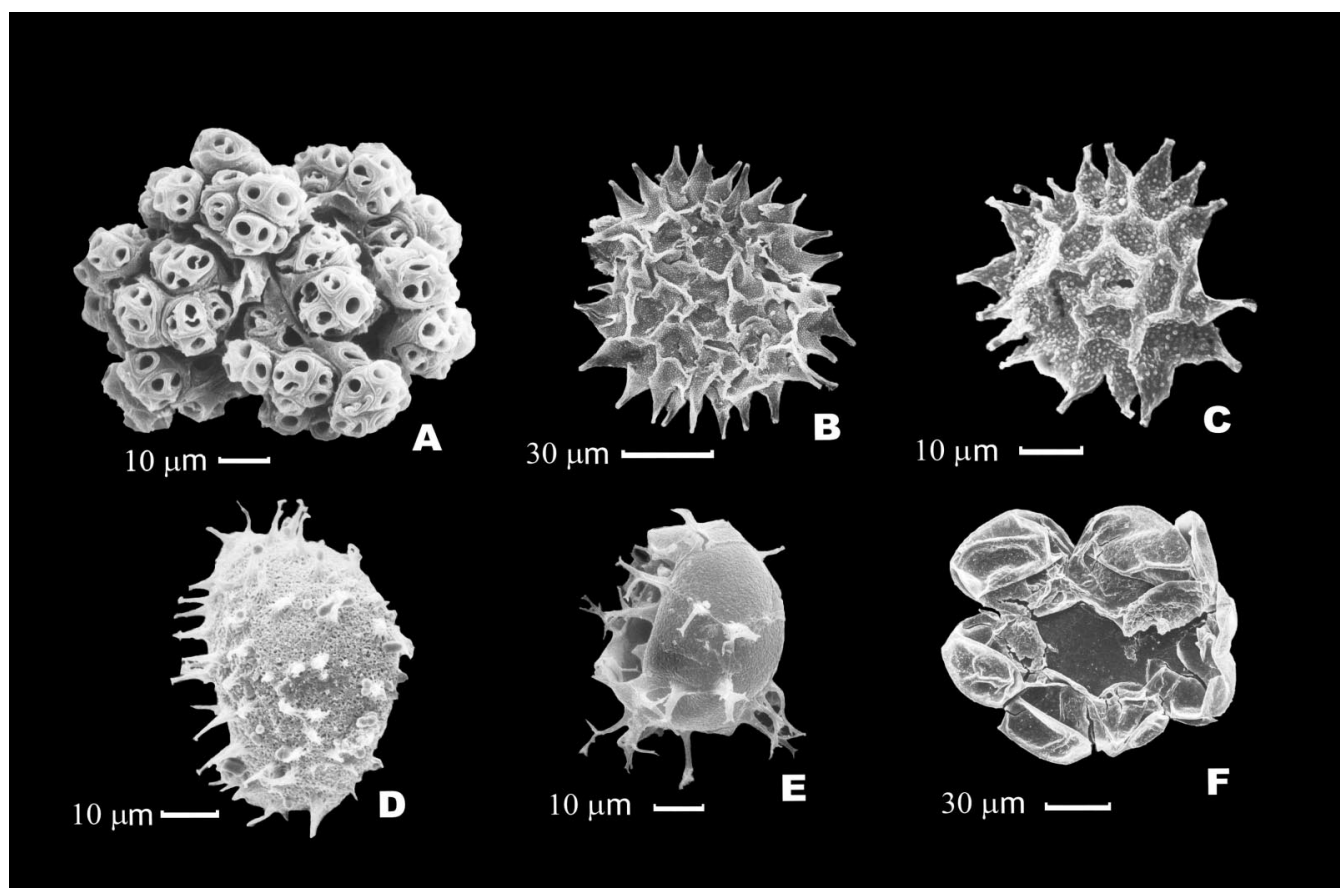

Figura 4. Palinomorfos característicos dos diferentes ambientes durante a evolução do corpo lagunar. A, Botryococcus braunii. B-C, Pediastrum boryanum. D, Operculodinium centrocarpum. E, Spiniferites mirabilis. F, Palinoforaminífero.

Figure 4. Characteristic palynomorphs from different environments during the evolution of lagoon. A, Botryococcus braunii. B-C, Pediastrum boryanum. C, Pediastrum boryanum; D, Operculodinium centrocarpum. E, Spiniferites mirabilis. F, Foraminiferal test linning. 


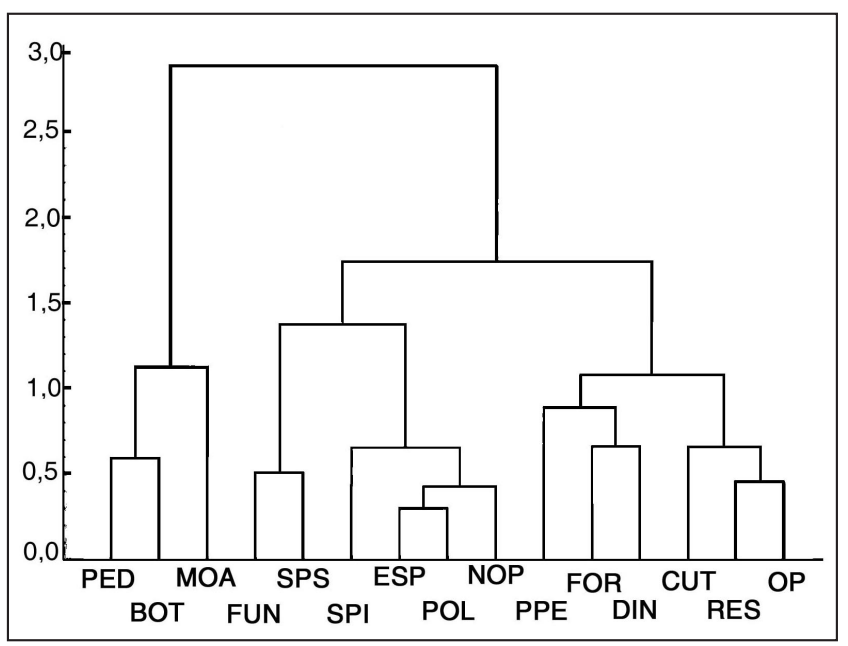

Figura 5. Dendograma obtido da análise de agrupamento modo- $R$ para os componentes da matéria orgânica particulada. PED, Pediastrum boryanum; BOT, Botryococus braunii; MOA, matéria orgânica amorfa; FUN, esporos de fungo; SPS, Spirogyra cf. scrobiculata; SPI, Spirogyra sp.; ESP, esporos; POL. grãos de pólen; NOP, fitoclastos não opacos; PPE, ovos de platelmintos; FOR, palinoforaminíferos; DIN, dinoflagelados; CUT, cutículas; RES, resinas; OP. fitoclastos opacos.

Figure 5. R-mode cluster analysis for the particulate organic matter components. PED, Pediastrum boryanum; BOT, Botryococcus braunii; AOM. amorphous organic matter; FUN, fungal spores; SPS, Spirogyra cf. scrobiculata; SPI, Spirogyra sp.; ESP, spores; POL, pollen grains; NOP, non opaque phytoclasts; PPE, plathyelminte eggs; FOR, foraminiferal test linnings; DIN, dinoflagellates; CUT, cuticles; RES, resins; OP, opaque phytoclasts. te em importância, com a segunda média percentual mais elevada para esta alga nos seis agrupamentos. A média dos componentes orgânicos que indicam o influxo fluvial é de 10,4\%.

Agrupamento 3. A média percentual de 81,6\% de MOA é a maior registrada entre os demais agrupamentos. O percentual indicativo de influxo fluvial é de 14,6\%. As amostras deste grupo representam o predomínio de condições redutoras com pouca contribuição do influxo fluvial.

Agrupamento 4. O percentual de MOA (42,5\%) é o fator com a maior média percentual neste grupo, seguido da média percentual de Botryococcus braunii (29\%), que é o maior percentual registrado para esta alga nos seis agrupamentos. A influência marinha está representada pela ocorrência de cistos de dinoflagelados em uma das cinco amostras do agrupamento (amostra 76). As amostras deste grupo indicam um ambiente favorável à preservação de MOA e influxo fluvial subordinado. As condições ambientais indicadas são semelhantes às do Agrupamento 2

Agrupamento 5. Neste grupo a média percentual dos componentes orgânicos que indicam o influxo fluvial $(71,6 \%)$ é o fator predominante. No entanto, o percentual de fitoclastos opa$\cos (40,7 \%)$ pode significar distância da área fonte e condições oxidantes. A média percentual de MOA, que indica condições redutoras, é de 13,8\%. A média de cistos de dinoflagelados e palinoforaminíferos, que representa a influência marinha é de 3,8\%, sendo este o segundo percentual mais alto dos seis agrupamentos. As amostras deste grupo indicam ambiente distante da área fonte e condições óxicas, com aporte fluvial subordinado e ambiente com influência marinha.

Agrupamento 6. Este grupo é constituído de oito amostras (Figura 6). A média percentual dos componentes orgânicos particulados que indicam o influxo fluvial é de $51 \%$ enquanto que a

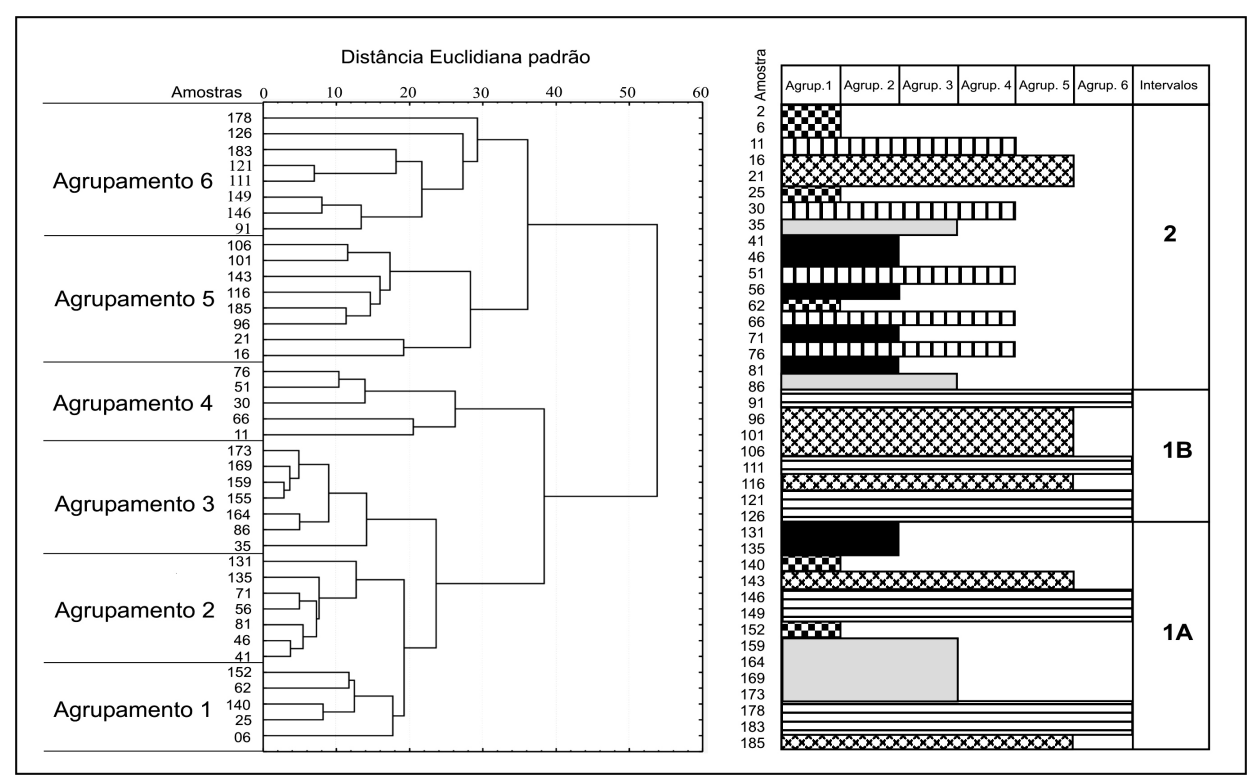

Figura 6. Dendograma obtido da análise de agrupamento modo- $Q$ para os componentes da matéria orgânica particulada (esquerda) e distribuição dos agrupamentos, em ordem estratigráfica, e intervalos propostos (direita).

Figure 6. Q-mode cluster analysis for the particulate organic matter (left) and stratigraphic plot of cluster grouping with proposed intervals (right). 
média percentual de MOA é de 38,9\%. A influência marinha indicada pela média percentual de palinoforaminíferos e cistos de dinoflagelados é de $4,9 \%$, a mais alta registrada nos seis agrupamentos. Na reconstituição paleoambiental, as amostras deste grupo indicam ambiente com influxo fluvial significativo, presença de condições redutoras, com a maior influência marinha ao longo da seqüência sedimentar estudada.

\section{CARACTERÍSTICAS E INTERPRETAÇÃO DAS PALINOFÁCIES}

Os seis agrupamentos foram plotados estratigraficamente e possibilitaram a identificação de três intervalos, que representam a evolução ambiental holocênica na lagoa dos Quadros, denominados, da base para o topo, intervalos 1A, 1B e 2 (Figura 6). A caracterização das palinofácies em cada intervalo foi feita com base nas variações dos percentuais dos componentes orgânicos particulados ao longo da seqüência sedimentar (Figura 7 e Tabela 1), bem como a partir dos agrupamentos definidos pela análise de agrupamento do modo- $Q$. Dessa forma, os dois grandes intervalos $(1 \mathrm{e} 2)$ refletem as principais mudanças ambientais registradas na lagoa dos Quadros, durante as fases transgressiva e regressiva, respectivamente.

Tabela 1. Média percentual dos principais agrupamentos da matéria orgânica particulada por intervalo estratigráfico, MOA, matéria orgânica amorfa; OP, fitoclastos opacos; NOP, fitoclastos não opacos; ESP+POL, esporos + grãos de pólen; DIN+FOR, dinoflagelados + palinoforaminíferos; BOT, Botryococcus braunii, PED, Pediastrum boryanum.

Table 1. Particulate organic matter percents of stratigraphic intervals, AOM, amorphous organic matter; OP, opaque phytoclasts; NOP, non opaque phytoclasts; ESP+POL, spores + pollen grains; DIN+FOR, dinoflagellates + foraminiferal test linnings; BOT, Botryococcus braunii, PED, Pediastrum boryanum

\begin{tabular}{c|ccccccc}
\hline $\begin{array}{c}\text { INTERVALO } \\
\text { Prof. (cm) }\end{array}$ & MOA & OP & NOP & $\begin{array}{c}\text { ESP+ } \\
\text { POL }\end{array}$ & $\begin{array}{c}\text { DIN+ } \\
\text { FOR }\end{array}$ & BOT & PED \\
\hline $\mathbf{2}(180-0)$ & 53,3 & 10,1 & 9,8 & 6,4 & 0,07 & 18,2 & 1,7 \\
$\mathbf{1 B}(260-180)$ & 26,5 & 35,2 & 16,5 & 6,1 & 7,7 & 6,7 & 0,9 \\
$\mathbf{1 A}(405-260)$ & 57,0 & 19,2 & 14,1 & 2,3 & 0,7 & 4,2 & 1,2 \\
\hline
\end{tabular}

\section{Intervalo 1A: Sistema Lagunar - Fase Transgressiva $(405-260 \mathrm{~cm})$}

A palinofácies deste intervalo apresenta o predomínio de MOA, fitoclastos opacos e fitoclastos não opacos (Tabela 1). A média percentual de cistos de dinoflagelados e palinoforaminíferos é $0,7 \%$. Os valores percentuais da curva da razão BOT/PED são próximos a zero com apenas dois picos percentuais em torno de $10 \%$ ao longo de todo o intervalo. A curva da média percentual de MOA mostra correlação inversa com a curva da média percentual de fitoclastos opacos. Em direção ao topo deste intervalo foi registrado o decréscimo no aporte de fitoclastos opacos (Figura 7). De acordo com a aná- lise de agrupamento do modo- $Q$, neste intervalo predominam amostras dos agrupamentos seis e três.

A MOA apresenta coloração em diversas tonalidades de marrom ao microcópio óptico em luz branca transmitida e níveis de fluorescência entre 3 e 5 de acordo com a escala de Tyson (1995).

A influência marinha se daria por meio de pulsos transgressivos, como mostra o registro de cistos de dinoflagelados e palinoforaminíferos, que não é contínuo ao longo do intervalo. Os baixos percentuais da curva da razão BOT/PED indicam tendências eutróficas para o corpo lagunar neste intervalo estratigráfico. Os dois picos que indicam tendência oligotrófica têm correlação com altos percentuais de MOA, com baixos valores de fitoclastos opacos em granulometria silte-argila arenoso. De acordo com Tyson (1995); a preservação da MOA ocorre preferencialmente em ambientes anóxicos até desóxicos. Tendo como base este parâmetro, os dois picos da curva da razão BOT/PED (10\%) poderiam ser interpretados como indicativos de condições desóxicas, já que a curva desta razão para o intervalo mostra claramente uma tendência eutrófica (anóxica) para o ambiente deposicional.

O intervalo $1 \mathrm{~A}$ pode ser correlacionado à Zona 1 identificada na lagoa Itapeva, interpretada como de influência marinha, tendo como base os valores acima de $0,2 \%$ de enxofre (S), num sistema estuarino/lagunar de fase transgressiva, cujos sedimentos foram depositados antes dos $6.460 \pm 40$ anos AP (Meyer et al., 2003).

\section{Intervalo 1B-Sistema Lagunar-Máximo Transgressivo Lagunar (260-180 cm)}

O predomínio de fitoclastos opacos sobre MOA e fitoclastos não opacos caracteriza a palinofácies do intervalo 1B. A média percentual de dinoflagelados e palinoforaminíferos de $7,7 \%$, é a maior em toda a seqüência sedimentar. A curva da razão BOT/PED mostra valores mais altos do que os valores percentuais do intervalo $1 \mathrm{~A}$. A correlação inversa entre a curva dos percentuais de MOA e fitoclastos opacos também é observada. O intervalo 1B é constituído por amostras dos agrupamentos seis e cinco, com predomínio de fitoclastos opacos e não opacos. A MOA neste intervalo apresentou coloração marrom-clara em luz branca transmitida e fluorescência equivalente ao nível 4.

O Máximo Transgressivo Lagunar é inferido com base no registro dos picos percentuais mais altos de cistos de dinoflagelados e palinoforaminíferos registrados ao longo da seqüência sedimentar. O predomínio de fitoclastos opacos na palinofácies do intervalo 1B pode estar associado a um ambiente oxidante, onde a MOA e partículas orgânicas não refratárias são degradadas mais rapidamente. A subida do nível relativo do mar aumentou a lâmina d'água no corpo lagunar, distanciando as amostras do intervalo $1 \mathrm{~B}$ da fonte fluvial. Ambientes deposicionais oxidantes são associados a sítios fluviais e nos topos dos deltas quando sujeitos a flutua- 
ções do nível d'água. Os fitoclastos opacos também são encontrados em grande quantidade em ambientes distais óxicos, pois estas partículas podem ser transportadas a grandes distâncias e por tempo prolongado (Tyson, 1995).

As curvas dos percentuais de fitoclastos opacos e MOA mostram uma tendência oscilatória com os picos percentuais de MOA coincidindo com a queda dos percentuais de fitoclastos opacos e picos percentuais de fitoclastos opacos relacionados à queda nos picos de MOA. A correlação entre as duas curvas mostra que a dispersão de MOA é feita pelas correntes que transportam os fitoclastos opacos. A tendência oligotrófica para o corpo lagunar neste intervalo é inferida a partir da elevação dos percentuais na curva da razão BOT/PED.

O intervalo $1 \mathrm{~B}$ da lagoa dos Quadros pode ser correlacionado à Zona 2 da lagoa Itapeva (Meyer et al., 2003), interpretada como um sistema lagunar, com o Máximo Transgressivo Lagunar caracterizado pela ocorrência de cistos de dinoflagelados, valores percentuais de enxofre (S) entre 0,4 e $0,8 \%$ com datação radiocarbônica (6.460 \pm 40 anos AP).

\section{Intervalo 2: Sistema Lagunar-Fase Regressiva $(\mathbf{1 8 0 - 0} \mathrm{cm})$}

A palinofácies deste intervalo mostra o predomínio de MOA e Botryococccus braunii. Neste intervalo são registrados os percentuais mais baixos de fitoclastos opacos e não opacos de toda a seqüência sedimentar. Os percentuais da curva da razão BOT/PED apresentam seis picos, com os índices mais elevados (Figura 7). Os picos da curva percentual de Pediastrum boryanum podem ser correlaciona- dos com os baixos valores percentuais da curva da razão BOT/PED. A coloração da MOA é marrom clara a escura em luz branca transmitida, com fluorescência equivalente aos níveis 3 e 4 . Nas amostras do topo deste intervalo há um aumento nos percentuais de grãos de pólen e esporos.

A fase regressiva é inferida neste intervalo com base nos baixos percentuais de cistos de dinoflagelados e palinoforaminíferos $(0,1 \%)$, estando o registro destes palinomorfos restrito às amostras da base do intervalo. Não foi verificada correlação entre as curvas dos percentuais de MOA e fitoclastos opacos. Os picos na curva dos percentuais de MOA têm correlação com a queda dos percentuais de Botryococcus. Os picos percentuais da curva de Botryococcus coincidem com a tendência a condições oligotróficas indicada pelo aumento dos percentuais na curva da razão BOT/PED. Isto mostra, em linhas gerais, que neste intervalo as condições mais óxicas favorecem a proliferação de Botryococcus e a queda dos percentuais de MOA, tendência comum na análise de palinofácies (Tyson, 1995). Os intervalos com tendência à condição eutrófica, indicada pela curva da razão BOT/PED, têm correlação positiva com a curva dos percentuais de Pediastrum (Figura 7), confirmando a preferência desta alga pelos ambientes eutróficos (Tyson, 1995). Percentuais elevados de grãos de pólen e esporos nas amostras do topo do intervalo registram a influência do Arroio Sanga Funda, que transporta palinomorfos das zonas mais internas da Planície Costeira, refletindo nestas amostras as condições observadas nos sedimentos recentes da lagoa dos Quadros.

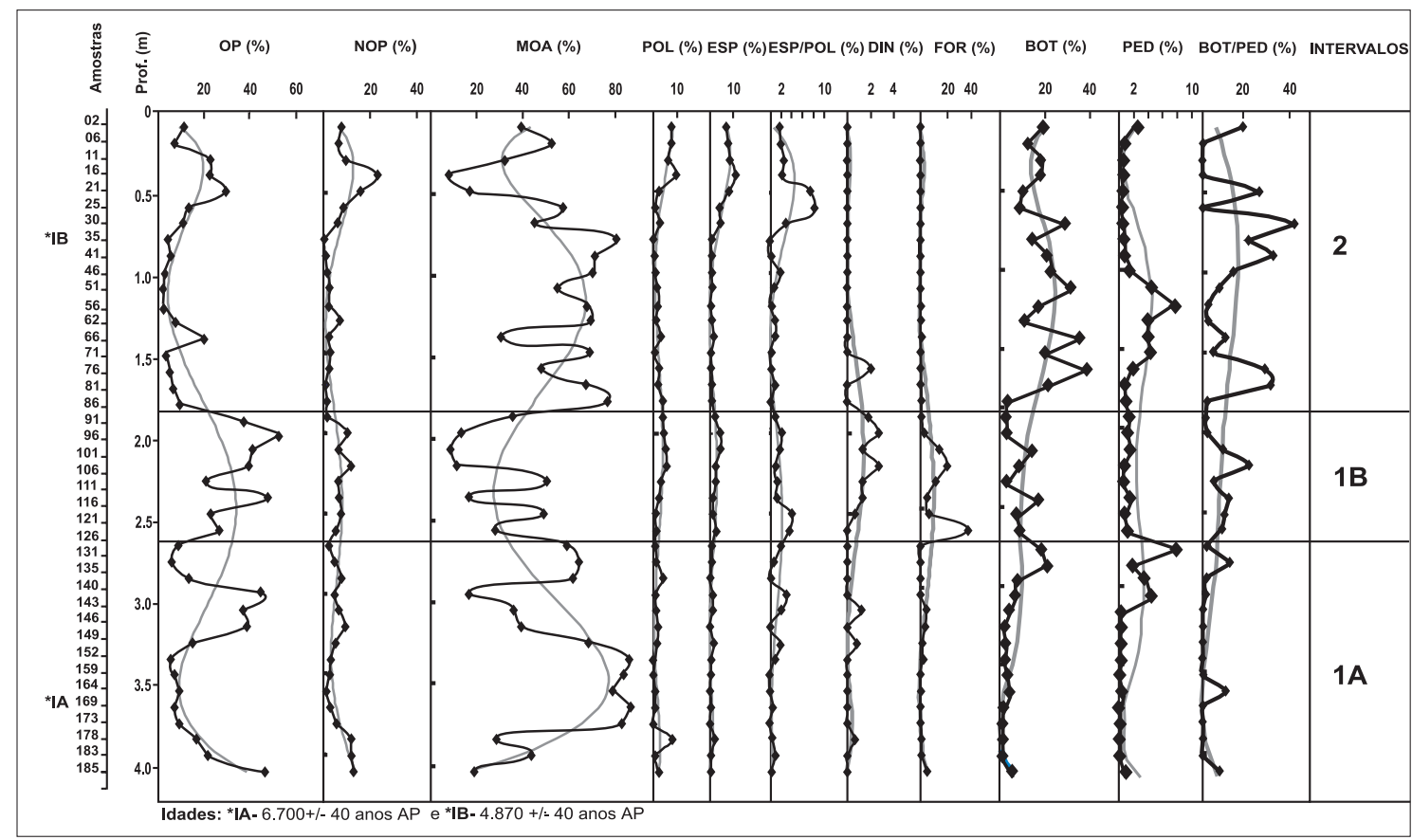

Figura 7. Percentuais dos principais agrupamentos da matéria orgânica particulada ao longo do testemunho. OP. fitoclastos opacos; NOP. fitoclastos não opacos; MOA. matéria orgânica amorfa; POL. grãos de pólen; ESP. esporos; ESP/POL. razão esporo/grãos de pólen; DIN. dinoflagelados; FOR. palinoforaminíferos; BOT. Botryococccus braunii; PED. Pediastrum boryanum; BOT/PED. razão BOT/PED.

Figure 7. Particulate organic matter group percents along the core. OP. opaque phytoclasts; NOP. non opaque phytoclasts; MOA. amorphous organic matter; POL. pollen grains; ESP. spores; ESP/POL. spores/pollen grains ratio; DIN. dinoflagellates; FOR. foraminiferal test linnings; BOT. Botryococccus braunii; PED. Pediastrum boryanum; BOT/PED. BOT/PED ratio. 
O intervalo 2 pode ser correlacionado às Zonas 3 e 4 da lagoa Itapeva (Meyer et al., 2003), onde condições de água doce foram inferidas para o corpo lagunar com base nos valores de carbono orgânico total (COT) e enxofre (S). Em ambas lagoas, as amostras do topo das seqüências, são marcadas pelo aumento da freqüência de grãos de pólen e esporos transportados por rios, que caracterizam o ambiente atual.

\section{DISCUSSÃO}

\section{Razão BOT/PED como indicadora de condições oligotró- ficas e/ou eutróficas}

De acordo com a quantidade de oxigênio e nutrientes disponíveis, os lagos são classificados em sistemas oligotróficos e/ou eutróficos. O lago oligotrófico constitui um sistema pouco produtivo onde a cadeia alimentar é pequena, com déficit de nutrientes; são lagos claros e com oxigênio disponível nas águas. O lago eutrófico é um sistema bastante produtivo que recebe aporte de nutrientes, são lagos escuros. Durante o processo de eutrofização, a quantidade de matéria orgânica aumenta, disponibilizando maior aporte de nutrientes, o fitoplâncton e o zooplâncton proliferam. O número de bactérias aumenta, o consumo de oxigênio é maior, caracterizando condições desóxicas/anóxicas (Schäfer, 1984).

Os fatores ambientais que controlam os gases dissolvidos nas águas dos lagos são a temperatura e pressão e a produção e consumo dos seres vivos.

Com relação à utilização dos percentuais da razão BOT/PED como indicadores de condições eutróficas ou oligotróficas, não há trabalhos que indiquem que percentual poderia ser considerado alto e, portanto, marcador de condições oligotróficas. Dessa forma, as elevações dos percentuais na curva da razão BOT/PED (Figura 7) foram interpretadas como tendência à condições oligotróficas, enquanto que a queda dos valores percentuais como tendência à condições eutróficas. A partir da comparação entre as curvas dos valores percentuais de Botryococcus, Pediastrum e razão $\mathrm{BOT} / \mathrm{PED}$, verifica-se que os picos percentuais do primeiro gênero correspondem aos picos de condições oligotróficas e que os picos percentuais de Pediastrum correspondem a condições eutróficas. Para uma correlação mais precisa destes valores percentuais com estas condições ambientais, faz-se necessária análise dos teores de $\mathrm{O}_{2}$ por amostra, que indicariam os parâmetros para condições óxicas.

A partir do princípio de que um lago oligotrófico teria um teor considerável de $\mathrm{O}_{2}$ dissolvido em suas águas de fundo (condições óxicas), uma correlação positiva entre baixos percentuais da curva de MOA e os picos da curva da razão BOT/PED seria esperada. No entanto, verifica-se que existe maior correlação entre a queda de valores percentuais de MOA e o aumento do aporte de fitoclastos (Figura 7), indicando que a dispersão dos fitoclastos, pelas correntes que os transportam, seria o fator que contribui significativamente para a queda nos percentuais de MOA.

\section{Variações do nível relativo do mar na PCRS}

Análises palinológicas em sedimentos lagunares e/ou lacustres e fluviais visando à reconstituição de paleoambientes que evoluíram, ao longo do Quaternário, influenciados pelas variações do nível relativo do mar têm sido realizadas na PCRS (e.g., Cordeiro \& Lorscheitter, 1994; Lorscheitter \& Dillenburg, 1998; Medeanic et al., 2000, 2001; Marques-Toigo et al., 2002).

Neves \& Lorscheitter (1995) não encontraram evidências de que o aumento do nível relativo do mar holocênico tenha atingido a turfeira de Terra de Areia. Provavelmente, isto se deve à sua localização em área mais elevada e a proteção dos cordões litorâneos pleistocênicos, que formaram uma barreira para a entrada da água do mar nesta turfeira.

Na laguna de Tramandaí, a análise palinológica evidenciou um máximo transgressivo do nível relativo do mar há cerca de 5.000 anos AP e uma outra transgressão, menos intensa, há cerca de 1.800 anos AP. (Lorscheitter \& Dillenburg, 1998).

Com base nas mudanças dos conjuntos de palinomorfos e em diatomáceas, Marques-Toigo et al. (2002) identificaram três estágios correspondentes a eventos transgressivos/regressivos na evolução ambiental holocênica nos sedimentos do vale do rio Maquiné. De acordo com os autores, o "Estágio T", registrado em sedimentos de granulometria argila síltica, silte argiloso e areia síltica, caracteriza-se pela ocorrência de cistos de dinoflagelados (Spiniferites e Operculodinium) e frústulas de diatomáceas marinhas e estaria relacionado à Última Transgressão Marinha. No entanto, não foram obtidas datações radiocarbônicas, dificultando a correlação destes estágios com outros eventos.

Na lagoa dos Quadros, a maior influência marinha é evidenciada no intervalo $1 \mathrm{~B}$, como resultado das variações do nível relativo do mar. De acordo com este registro, a Última Transgressão Marinha Lagunar ocorreu no intervalo de tempo entre $6.700 \pm 40$ anos AP e $4.870 \pm 40$ anos AP.

Estes resultados estão de acordo com o modelo de evolução da Barreira IV na localidade de Curumim que iniciou sua progradação em torno de 7.000 anos $\mathrm{AP}$, devido ao balanço positivo na acomodação dos sedimentos, quando o nível relativo do mar ainda estava subindo, no período próximo ao final da Última Transgressão Marinha holocênica. (Dillenburg et al., no prelo).

A segunda transgressão marinha holocênica registrada em torno de 1.800 anos AP na laguna da Tramandaí (Lorscheitter \& Dillenburg, 1998) não foi evidenciada na lagoa dos Quadros. A ausência deste registro pode estar associada à possibilidade de os corpos lagunares situados ao norte da laguna de Tramandaí já estarem segmentados e devido à presença da Barreira IV.

Fora da PCRS, a correlação mais provável das palinofácies identificadas na lagoa dos Quadros é com a seqüência holocênica de rio Varela, no canal de Beagle, Argentina (Grill et al., 2002). Estes autores identificaram sete pa- 
linofácies, que correspondem à evolução paleoambiental desta área, influenciada pelas variações relativas do nível do mar. Os resultados obtidos neste estudo mostram que na base da seqüência, o ambiente marinho próximo da costa evoluiu a um ambiente marinho nerítico externo (palinofácies A e B), a lacustre continental (palinofácies C), seguido de um ambiente pantanoso influenciado pelo aumento do nível do mar (palinofácies D) e condições fluviais/estuarinas (palinofácies E), seguido de ambiente fluvial (palinofácies F), para o topo da seqüência, o solo atual (palinofácies G). Em linhas gerais, as palinofácies identificadas, na seqüência sedimentar da lagoa dos Quadros, podem ser correlacionadas, em parte, com as palinofácies C, D, E e F de Grill et al.(2002).

\section{CONSIDERAÇÕES FINAIS}

A matéria orgânica particulada recuperada dos sedimentos do testemunho de sondagem QU-RS-B09 da lagoa dos Quadros reflete um sistema deposicional constituído de um corpo lagunar com pulsos transgressivos identificados pelo registro de componentes orgânicos particulados marinhos (e.g., cistos de dinoflagelados, palinoforaminíferos) e que evoluiu para condições lacustres em direção ao topo da seção durante o Holoceno. As evidências que reforçam este modelo são:

Ocorrência de cistos de dinoflagelados, Operculodinium centrocarpum e Spiniferites mirabilis, espécies características de ambientes marinhos costeiros, com flutuações de salinidade e estuarinos e em percentuais que não ultrapassaram $4 \%$. O registro descontínuo de cistos de dinoflagelados e de palinoforaminíferos indica os pulsos transgressivos marinhos.

Os percentuais mais baixos de Botryococcus braunii são registrados durante a fase transgressiva, enquanto que, os percentuais mais elevados ocorrem na fase regressiva. As variações na curva dos percentuais de Botryococcus braunii evidenciam a tolerância desta alga às variações de salinidade, e o aumento do registro desta alga na fase regressiva, sua natureza dulciaquícola.

O registro de influxo fluvial é marcado pelos fitoclastos não opacos, cutículas e esporomorfos de origem terrestre.

A partir da correlação entre as variações dos percentuais dos tipos de componentes da matéria orgânica nos três intervalos identificados, que representam os diferentes ambientes deposicionais na evolução holocênica da lagoa dos Quadros, foi possível estabelecer as seguintes interpretações para os intervalos propostos:

Intervalo 1A. Caracterizado por uma palinofácies com predomínio de MOA, fitoclastos opacos e não opacos, está associada ao Sistema Lagunar em Fase Transgressiva.

Intervalo 1B. Palinofácies correspondente a fitoclastos opacos, MOA e fitoclastos não opacos, representando o Sistema Lagunar e o Máximo Transgressivo Lagunar.
Intervalo 2. Predomínio de MOA e Botryococcus braunii, que registra o Sistema Lagunar em Fase Regressiva, e, em direção ao topo, o lago costeiro com aumento de grãos de pólen e esporos

A maior influência marinha no ambiente lagunar é evidenciada no intervalo $1 \mathrm{~B}$, como resultado das variações do nível relativo do mar nesta área da PCRS. De acordo com este registro, a Última Transgressão Marinha Lagunar ocorreu no intervalo de tempo entre $6.700 \pm 40$ anos AP e $4.870 \pm$ 40 anos AP na seqüência sedimentar da lagoa dos Quadros.

\section{AGRADECIMENTOS}

Este trabalho foi realizado no âmbito do projeto "Evolução do Ecossistema da Mata Atlântica e da Mata de Araucaria nas áreas costeiras do sul do Brasil e sua relação com as mudanças climáticas e ação antrópica no Holoceno", desenvolvido em parceria entre a Universidade Federal do Rio Grande do Sul e a Universidade de Tübingen com recursos do programa CAPES/ DAAD/PROBRAL. Agradecemos a Ari Roisenberg e Volker Mosbrugger, o apoio no aperfeiçoamento do conhecimento científico e formação pessoal dos estudantes brasileiros e alemães, a Marcelo Carvalho e ao revisor anônimo pelas críticas e sugestões ao manuscrito; e ao CNPq pela concessão de bolsa (KM). Este trabalho é dedicado a Marleni Marques Toigo (in memoriam) em reconhecimento à sua contribuição na produção científica e transmissão de conhecimentos às novas gerações.

\section{REFERÊNCIAS BIBLIOGRÁFICAS}

Angulo, R.J. \& Lessa, G.C., 1997. The Brazilian sea-level curves: a critical review with emphasis on the curves from Paranaguá and Cananéia regions. Marine Geology, 140:141-166.

Angulo, R.J.; Giannini, P.C.F.; Suguio, K. \& Pesenda, L.C.R. 1999 Relative sea-level changes in the last 5500 years in southern Brazil (Laguna-Imbituba region, Santa Catarina State) based on vermitid ${ }^{14} \mathrm{C}$ ages. Marine Geology, 159:323-339.

Bauermann, S.G.; Marques-Toigo, M.; Behling, H. \& Neves, P.C.P. 2002. Aspectos tafonômicos em palinologia de Quaternário. Pesquisas (Série Botânica), 52:223-239.

Carvalho, M.A. 2001. Paleoenvironmental reconstruction based on palynology and palynofacies analyses of upper Aptian-Middle Albian sucession from Sergipe Basin, northeaster Brazil. Ruprecht-Karl Universität Heidelberg, Tese de Doutoramento, $160 \mathrm{p}$.

Cordeiro, S.H. \& Lorscheitter, M.L. 1994. Palynology of Lagoa dos Patos sediments, Rio Grande do Sul, Brazil. Journal of Paleolimnology, 10:35-42.

Corrêa, I.C.S. 1995. Les variations du niveu de la mer durant lês derniers 17.500 ans BP: 1'exemple de la plate-forme continentale du Rio Grande do Sul-Brésil. Marine Geology, 130:163-178.

Dillenburg, S.R.; Roy, P.S.; Cowell, P.J. \& Tomazelli, J.L. 2000. Influence of antecedent topography on coastal evolution as tested by the shoreface translation barrier model (STM). Journal of Coastal Research, 16(1):71-81. 
Dillenburg, S.R.; Tomazelli, L.J.; Hesp, P.A.; Barboza, E.G.; Clerot, L.C.P. \& Silva, D.B. no prelo. Stratigraphy and Evolution of a Prograded Transgressive Dunefield Barrier in Southern Brazil. Journal of Coastal Research, Special Issue 39.

Ghignone, J.I. 1960. Reconhecimento gravimétrico na bacia de Pelotas. Boletim Técnico da Petrobras, 3(2):73-79.

Gregory, W.A. \& Hart, G.F. 1990. Sub-division of Wilcox Group (Sabinian) argillaceous sediments using particulate organic matter. Palynology, 14:105-121.

Grill, S.; Borromei, A.M.; Quattrocchio, M.; Coronato, A.; Bujalesky, G. \& Rabassa, J. 2002. Palynological and sedimentological analysis of Recent sediments from Rio Varela, Beagle Channel, Tierra del Fuego, Argentina. Revista Española de Micropaleontología, 34(2):145-161.

Lorscheitter, M. L. \& Dillenburg, S. R. 1998. Holocene palaeoenvironments of the northern coastal plain of Rio Grande do Sul, Brazil, reconstructed from palynology of Tramandaí lagoon sediments. Quaternary of South America and Antartic Peninsula, 1:39-67.

Martin, L.; Suguio, K. \& Flexor, J.M. 1979. Le Quaternaire marin du littoral brésilien entre cananéia (SP) et barra de Guaratiba (RJ). In: INTERNATIONAL SYMPOSIUM ON COASTAL EVOLUTION IN THE QUATERNARY. 1979. Proceedings, São Paulo, Brasil. p. 231-331.

Marques-Toigo, M.; Medeanic, S.; Mosbrugger, V. \& Ashraf, A.R. 2002. Palaeoenvironmental changes in the Maquiné River Valley, RS, Brazil, during the Holocene according to Palynological data. Revista Brasileira de Paleontologia, 3:36-47.

Martin, L.; Bittencourt, A.C.S.P.; Dominguez, J.M.L.; Flexor, J.M. \& Suguio, K. 1998. Oscillations or not oscillations, that is the question: comment on Angulo, R. J. and Lessa, G. C. "The Brazilian sea-level curves: a critical review with emphasis on the curves from Paranaguá and Cananéia regions." [Mar. Geol. 140: 141-166]. Marine Geology, 150:179-187.

Medeanic, S.; Marques-Toigo, M. \& Ashraf, A.R. 2000. The use of fossil algae for palaeoenvironmental reconstruction during the late Holocene in the Maquiné River Valley, RS, Brazil. Revista Universidade de Guarulhos Geociências, 6:168-172.

Medeanic, S.; Dillenburg, S.R. \& Toldo Júnior, E. E. 2001. Novos dados palinológicos da Trangressão Marinha Pós-Glacial em sedimentos da laguna dos Patos, RS, Brasil. Revista Universidade de Guarulhos Geociencias, 6(6):64-76.

Menezes, T. R. 2002. Aplicação de parâmetros palinofaciológicos e organogeoquímicos na reconstituição paleoambiental do talude continental brasileiro recente na Bacia de Campos, RJ. Programa de Pós-Graduação em Geologia, Universidade Federal do Rio de Janeiro, Dissertação de Mestrado, 174 p.

Mendonça Filho, J.G. 1999. Aplicação de estudos de palinofácies e fácies orgânica em rochas do Paleozóico da Bacia do Paraná, Sul do Brasil. Programa de Pós-Graduação em Geociências, Universidade Federal do Rio Grande do Sul, Tese de Doutorado, 338 p.

Mendonça Filho, J.G.; Carvalho, M.A. \& Menezes, T.R. 2002. Palinofácies: In: T.L. Dutra (ed.) Técnicas e procedimentos de tra- balho com fósseis e formas modernas comparativas, Editora Unisinos, p. 20-24.

Meyer, K.E.B.; Reichhart, K.; Ashraf, A.R.; Marques-Toigo, M.; Souza, P.A. \& Mosbrugger, V. 2003. Evolução ambiental holocênica da lagoa Itapeva, Planície Costeira do Rio Grande do Sul, Brasil. In: CONGRESSO DA ASSOCIAÇÃO BRASILEIRA DE ESTUDOS DO QUATERNÁRIO, XI, 2003. Livro de Resumos, Recife, ABEQUA, p. 104-105.

Neves, P.C.P. das, \& Lorscheitter, M. L. 1995. Upper Quaternary palaeoenvironments in the Northern Coastal Plain of Rio Grande do Sul, Brazil. Quaternary of South America and Antartic Peninsula, 9:39-67.

Pasley, M.A.; Gregory, G.W. \& Hart, G.F. 1991. Organic matter variations in transgressive and regressive shales. Organic Geochemistry, 17:483-509.

Schäfer, A. 1984. Fundamentos de Ecologia e Biogeografia das águas continentais. Porto Alegre: UFRGS, 532 p.

Stancliffe, R.P.W. 1989. Microforaminiferal linings: Their classification, biostratigraphy and paleoecology, with special reference to specimens from British Oxfordian sediments. Micropaleontology, 35(4):337-352.

Suguio, K.; Martin, L.; Bittencourt, A. C. S. P.; Dominguez, J.M.L.; Flexor, J.M. \& Azevedo, A.E.G. 1985. Flutuações do nível relativo do mar durante o Quaternário Superior ao longo do litoral brasileiro e suas implicações na sedimentação costeira. Revista Brasileira de Geociências, 15(4):273-286.

Tomazelli, L. J. \& Villwock, J.A. 2000. O Cenozóico costeiro do Rio Grande do Sul. In: M. Holz, \& L. F. De Ros (eds.). Geologia do Rio Grande do Sul. Porto Alegre: Edições CIGO/UFRGS, p. 375-406.

Traverse, A. 1994. Sedimentation of palynomorphs and palynodebris: an introduction. In: A. Traverse (ed.) Sedimentation of Organic Particles. Cambridge University Press, p. 1-8.

Tyson, R.V. 1993. Palynofacies analysis. In: D.G. Jenkins (ed.) Applied Micropaleontology. Kluver, p. 153-191.

Tyson, R.V. 1995. Sedimentary organic matter: Organic facies and palynofacies analysis. London, Chapman \& Hall, $615 \mathrm{p}$.

Tyson, R.V. 1996. Sequence stratigraphical interpretation of organic facies variations in marine siliciclastic systems: general principles and application to the onshore Kimmeridge Clay Formation, UK. In: S.P. Hesselbo \& D.N. Parkinson (eds) Sequence Stratigraphy in British Geology, London Geological Society, Special Publication 103, p. 75-96.

Valentin, J.L. 2000. Ecologia numérica: uma introdução à análise multivariada de dados ecológicos. Rio de Janeiro, Interciência, 117 p.

Villwock, J. A. 1984. Geology of the Coastal Province of Rio Grande do Sul, Southern Brazil: A Synthesis. Pesquisas, 16:5-49.

Villwock, J.A. \& Tomazelli, L.J. 1995. Geologia costeira do Rio Grande do Sul. Notas Técnicas, 8:1-45.

Wiley, E.O. 1981. Phylogenetics: Theory and practice of phylogenetic systematics. Nova York, J. Wiley and Sons, 403 p. 
Anexo 1. Lista das algas identificadas neste estudo.

Appendix 1. List of the identified algae in this study.

Botryococcus Kützing 1849, Botryococcus braunii Kützing 1849, Debarya Witrock emend. Transeau 1934, Mougeotia C.A. Agardh 1824, Operculodinium centrocarpum (Deflandre \& Cookson) Wall 1967, Pediastrum Meyen 1829, Pediastrum boryanum (Turpin) Meneghini 1840, Spiniferites mirabilis (Rossignol) Sarjeant 1970, Spirogyra Link 1820, Tipo Zygnema C.A. Agardh 1824

Anexo 2. Média percentual dos principais agrupamentos da matéria orgânica particulada em cada um dos seis agrupamentos identificados na análise de agrupamento do modo-Q. OP, fitoclastos opacos; NOP, fitoclastos não opacos; CUT, cutículas; RES, resinas; PAL, grãos de pólen; SPO, esporos; DIN, cistos de dinoflagelados; FOR, palinoforaminíferos; BOT, Botryococcus braunii; PED, Pediastrum boryanum; SPS, Spirogyra cf, scrobiculata; SPI, Spirogyra sp.; FUN, esporos de fungo; PPE, ovos de platelmintos,

Appendix 2. Percents of particulate organic matter components for the six groups of Q-mode cluster analysis. OP, opaque phytoclasts; NOP, non opaque phytoclasts; CUT, cuticles; RES, resins; PAL, pollen grains; SPO, spores; DIN, dinoflagellates; FOR, foraminiferal test linnings; BOT, Botryococcus braunii; PED, Pediastrum boryanum; SPS, Spirogyra cf, scrobiculata; SPI, Spirogyra sp.; FUN, fungal spores; PPE, Platyelminthe eggs,

\begin{tabular}{|c|c|c|c|c|c|c|c|c|c|c|c|c|c|c|c|}
\hline Agrupamento 6 & OP & NOP & CUT & RES & MOA & PAL & SPO & DIN & FOR & BOT & PED & SPS & SPI & FUN & PPE \\
\hline B9-91 & 30,77 & 1,71 & 10,26 & 10,68 & 35,47 & 4,27 & 2,14 & 0,85 & 0,43 & 1,71 & 1,28 & 0,43 & 0,00 & 0,00 & 0,00 \\
\hline B9-111 & 20,67 & 6,67 & 2,33 & 4,00 & 50,33 & 3,33 & 2,33 & 0,67 & 6,67 & 1,67 & 0,33 & 0,33 & 0,00 & 0,00 & 0,67 \\
\hline B9-121 & 23,00 & 7,67 & 3,33 & 3,67 & 49,00 & 0,67 & 1,33 & 0,33 & 3,67 & 6,33 & 0,67 & 0,00 & 0,33 & 0,00 & 0,00 \\
\hline B9-126 & 26,67 & 5,67 & 4,33 & 2,33 & 27,67 & 1,33 & 2,33 & 0,00 & 20,33 & 8,33 & 1,00 & 0,00 & 0,00 & 0,00 & 0,00 \\
\hline B9-146 & 37,06 & 6,47 & 3,53 & 9,41 & 35,88 & 1,18 & 1,18 & 0,59 & 2,35 & 2,35 & 0,00 & 0,00 & 0,00 & 0,00 & 0,00 \\
\hline B9-149 & 38,46 & 9,62 & 3,85 & 3,85 & 39,42 & 1,92 & 0,00 & 0,00 & 1,92 & 0,00 & 0,00 & 0,96 & 0,00 & 0,00 & 0,00 \\
\hline B9-183 & 21,67 & 12,00 & 17,67 & 2,67 & 44,33 & 0,67 & 0,33 & 0,00 & 0,33 & 0,00 & 0,00 & 0,00 & 0,00 & 0,33 & 0,00 \\
\hline B9-178 & 16,67 & 11,33 & 5,33 & 9,67 & 28,33 & 8,33 & 2,00 & 0,33 & 0,33 & 0,00 & 0,00 & 1,33 & 0,00 & 16,33 & 0,00 \\
\hline Média & 26,90 & 7,60 & 6,50 & 5,85 & 38,90 & 2,70 & 1,50 & 0,40 & 4,50 & 2,60 & 0,40 & 0.4 & 0,03 & 2,08 & 0,04 \\
\hline \multicolumn{16}{|l|}{ Agrupamento 5} \\
\hline B9-16 & 22,22 & 23,33 & 0,00 & 7,78 & 7,78 & 10,00 & 11,11 & 0,00 & 0,00 & 16,67 & 0,00 & 0,00 & 1,11 & 0,00 & 0,00 \\
\hline B9-21 & 29,33 & 16,00 & 5,67 & 11,00 & 17,00 & 2,33 & 8,33 & 0,00 & 0,00 & 8,33 & 0,33 & 0,00 & 1,00 & 0,00 & 0,67 \\
\hline B9-96 & 52,33 & 10,67 & 4,33 & 3,67 & 13,33 & 4,67 & 4,67 & 1,33 & 1,67 & 2,00 & 1,00 & 0,33 & 0,00 & 0,00 & 0,00 \\
\hline B9-101 & 41,00 & 6,67 & 3,67 & 7,00 & 8,67 & 5,33 & 4,67 & 0,67 & 8,33 & 11,67 & 1,33 & 1,00 & 0,00 & 0,00 & 0,00 \\
\hline B9-106 & 39,33 & 12,00 & 8,00 & 1,00 & 11,33 & 5,67 & 2,67 & 1,33 & 11,33 & 6,67 & 0,33 & 0,00 & 0,00 & 0,00 & 0,33 \\
\hline B9-116 & 47,67 & 7,00 & 2,33 & 2,67 & 16,33 & 2,33 & 1,33 & 0,67 & 3,00 & 15,00 & 1,33 & 0,33 & 0,00 & 0,00 & 0,00 \\
\hline B9-143 & 46,67 & 4,89 & 5,78 & 14,22 & 16,44 & 0,89 & 1,33 & 0,00 & 0,00 & 5,78 & 4,00 & 0,00 & 0,00 & 0,00 & 0,00 \\
\hline B9-185 & 46,33 & 13,00 & 8,33 & 1,33 & 19,00 & 2,67 & 0,33 & 0,00 & 2,67 & 4,67 & 0,67 & 0,00 & 0,00 & 1,00 & 0,00 \\
\hline Média & 40,70 & 11,60 & 4,80 & 6,10 & 13,80 & 4,20 & 4,20 & 0,50 & 3,30 & 8,80 & 1,10 & 0,20 & 0,30 & 0,20 & 0,20 \\
\hline \multicolumn{16}{|l|}{ Agrupamento 4} \\
\hline B9-11 & 22,09 & 8,91 & 0,00 & 1,94 & 33,72 & 6,59 & 8,53 & 0,00 & 0,00 & 17,44 & 0,00 & 0,78 & 0,00 & 0,00 & 0,00 \\
\hline B9-30 & 10,67 & 6,00 & 2,33 & 0,00 & 45,00 & 3,00 & 4,33 & 0,00 & 0,00 & 27,00 & 0,67 & 0,00 & 1,00 & 0,00 & 0,00 \\
\hline B9-51 & 2,67 & 2,67 & 0,33 & 1,67 & 55,00 & 2,00 & 0,67 & 0,00 & 0,00 & 30,33 & 4,33 & 0,00 & 0,33 & 0,00 & 0,00 \\
\hline B9-66 & 19,33 & 2,33 & 4,00 & 1,33 & 30,67 & 3,33 & 1,67 & 0,00 & 0,00 & 34,00 & 3,33 & 0,00 & 0,00 & 0,00 & 0,00 \\
\hline B9-76 & 5,00 & 2,33 & 1,67 & 1,00 & 48,00 & 2,67 & 0,33 & 1,00 & 0,00 & 36,67 & 1,33 & 0,00 & 0,00 & 0,00 & 0,00 \\
\hline Média & 11,90 & 4,50 & 1,70 & 1,25 & 42,50 & 3,50 & 3,10 & 0,20 & 0,00 & 29,00 & 1,90 & 0,15 & 0,30 & 0,00 & 0,00 \\
\hline \multicolumn{16}{|l|}{ Agrupamento 3} \\
\hline B9-35 & 4,00 & 0,33 & 0,00 & 0,00 & 80,67 & 0,00 & 0,67 & 0,00 & 0,00 & 13,33 & 0,67 & 0,00 & 0,00 & 0,00 & 0,33 \\
\hline B9-86 & 9,00 & 1,67 & 1,67 & 4,00 & 76,67 & 4,00 & 0,67 & 0,00 & 0,33 & 1,33 & 0,67 & 0,00 & 0,00 & 0,00 & 0,00 \\
\hline B9-159 & 7,00 & 2,67 & 3,67 & 0,33 & 84,00 & 0,00 & 0,33 & 0,00 & 0,00 & 2,00 & 0,00 & 0,00 & 0,00 & 0,00 & 0,00 \\
\hline
\end{tabular}




\begin{tabular}{|c|c|c|c|c|c|c|c|c|c|c|c|c|c|c|c|}
\hline Agrupamento 3 & OP & NOP & CUT & RES & MOA & PAL & SPO & DIN & FOR & ВOT & PED & SPS & SPI & FUN & PPE \\
\hline B9-164 & 9,33 & 1,33 & 3,33 & 2,33 & 79,00 & 1,00 & 0,00 & 0,00 & 0,00 & 3,33 & 0,33 & 0,00 & 0,00 & 0,00 & 0,00 \\
\hline B9-169 & 7,00 & 3,00 & 1,00 & 0,67 & 86,67 & 1,00 & 0,33 & 0,00 & 0,00 & 0,33 & 0,00 & 0,00 & 0,00 & 0,00 & 0,00 \\
\hline B9-173 & 9,00 & 5,33 & 1,67 & 1,00 & 83,00 & 0,00 & 0,00 & 0,00 & 0,00 & 0,00 & 0,00 & 0,00 & 0,00 & 0,00 & 0,00 \\
\hline Média & 7,60 & 2,40 & 1,90 & 1,40 & 81,60 & 1,00 & 0,30 & 0,00 & 0,05 & 3,40 & 0,30 & 0,00 & 0,00 & 0,00 & 0,05 \\
\hline \multicolumn{16}{|l|}{ Agrupamento 2} \\
\hline B9-41 & 5,33 & 0,67 & 0,33 & 0,00 & 71,67 & 0,00 & 0,67 & 0,00 & 0,00 & 20,67 & 0,67 & 0,00 & 0,00 & 0,00 & 0,00 \\
\hline B9-46 & 2,67 & 1,67 & 0,67 & 0,00 & 70,33 & 0,33 & 0,33 & 0,00 & 0,00 & 22,33 & 1,67 & 0,00 & 0,00 & 0,00 & 0,00 \\
\hline B9-56 & 2,00 & 2,33 & 1,33 & 0,67 & 67,67 & 2,33 & 0,00 & 0,00 & 0,00 & 16,33 & 7,00 & 0,00 & 0,33 & 0,00 & 0,00 \\
\hline B9-71 & 3,32 & 2,99 & 1,33 & 0,00 & 69,10 & 0,00 & 0,33 & 0,00 & 0,00 & 18,60 & 3,99 & 0,00 & 0,00 & 0,00 & 0,33 \\
\hline B9-81 & 6,33 & 1,00 & 1,67 & 0,00 & 67,33 & 2,00 & 1,00 & 0,00 & 0,00 & 20,00 & 0,67 & 0,00 & 0,00 & 0,00 & 0,00 \\
\hline B9-131 & 8,67 & 2,33 & 1,00 & 3,33 & 59,00 & 0,67 & 0,67 & 0,00 & 0,00 & 17,00 & 7,33 & 0,00 & 0,00 & 0,00 & 0,00 \\
\hline B9-135 & 6,00 & 5,00 & 0,00 & 1,00 & 64,33 & 1,67 & 0,67 & 0,00 & 0,00 & 19,33 & 1,67 & 0,00 & 0,33 & 0,00 & 0,00 \\
\hline Média & 4,90 & 2,30 & 0,90 & 0,70 & 67,10 & 1,00 & 0,60 & 0,00 & 0,00 & 19,20 & 3,20 & 0,00 & 0,07 & 0,00 & 0,03 \\
\hline \multicolumn{16}{|l|}{ Agrupamento 1} \\
\hline B9-02 & 11,00 & 7,67 & 4,33 & 2,33 & 39,33 & 7,67 & 7,00 & 0,00 & 0,00 & 17,67 & 1,00 & 1,00 & 0,33 & 0,00 & 0,67 \\
\hline B9-06 & 7,00 & 6,67 & 2,67 & 3,67 & 52,33 & 8,00 & 7,67 & 0,00 & 0,00 & 10,67 & 0,00 & 1,33 & 0,00 & 0,00 & 0,00 \\
\hline B9-25 & 13,33 & 8,67 & 5,00 & 3,00 & 57,33 & 1,00 & 4,00 & 0,00 & 0,00 & 7,33 & 0,00 & 0,33 & 0,00 & 0,00 & 0,00 \\
\hline B9-62 & 7,00 & 7,00 & 1,67 & 0,67 & 69,33 & 1,33 & 0,67 & 0,00 & 0,00 & 8,67 & 3,67 & 0,00 & 0,00 & 0,00 & 0,00 \\
\hline B9-140 & 13,33 & 7,67 & 3,67 & 0,67 & 61,67 & 4,00 & 0,00 & 0,00 & 0,00 & 5,33 & 3,33 & 0,33 & 0,00 & 0,00 & 0,00 \\
\hline B9-152 & 15,02 & 5,14 & 3,16 & 1,98 & 68,77 & 1,58 & 1,58 & 0,40 & 0,79 & 1,58 & 0,00 & 0,00 & 0,00 & 0,00 & 0,00 \\
\hline Média & 11,40 & 7,10 & 3,40 & 2,00 & 58,40 & 3,80 & 3,50 & 0,06 & 0,20 & 8,40 & 1,20 & 0,50 & 0,03 & 0,00 & 0,01 \\
\hline
\end{tabular}

